\title{
Diagnostic imaging of intra-abdominal cyst in heifer using the computed tomography
}

\author{
Konosuke OTOMARU ${ }^{1) *}$, Takuro FUJIKAWA ${ }^{1)}$, Yasuo SAITO ${ }^{1)}$, Takaaki ANDO ${ }^{1)}$, Takeshi OBI ${ }^{1)}$, Naoki MIURA ${ }^{1)}$ and \\ Chikara KUBOTA ${ }^{1)}$
}

1) Joint Faculty of Veterinary Medicine, Kagoshima University, 1-21-24 Korimoto, Kagoshima 890-0065, Japan

(Received 17 March 2015/Accepted 17 April 2015/Published online in J-STAGE 30 April 2015)

ABSTRACT. A 10-month-old Japanese black heifer was diagnosed as having an intra-abdominal cyst using computed tomography (CT). Through a posterior ventral midline incision, the cyst was removed, and the heifer completely recovered after the surgery. CT scans enabled detection of the intra-abdominal cyst and measurements of the diameter of the cyst before the surgery.

KEY WORDS: computed tomography, heifer, intra-abdominal cyst

doi: 10.1292/jvms.15-0153; J. Vet. Med. Sci. 77(9): 1191-1193, 2015

The number of case reports involving diagnosis with computed tomography (CT) has been increasing in both companion and production animals. There have been numerous reports on the diagnosis of abdominal diseases in small animals using CT $[1,3,5,8,11]$. In production animals, however, reports on diagnosis of abdominal abnormalities using CT [7, 10] have been limited. Therefore, we want to report a case of intra-abdominal cyst in Japanese Black heifer diagnosed by CT.

A 10-month-old Japanese Black heifer with $247 \mathrm{~kg}$ body weight showed urinary tenesmus since 13 days before it was presented for the first consultation at the joint faculty of veterinary medicine, Kagoshima University. At the first examination, rectal temperature, pulse rate and heartbeat were within the normal range. But, total leukocyte count was $14,700 / \mu l$. It was slightly higher than the reference value $(4,000-12,000 / \mu l)[6]$. Serum biochemical analysis showed normal levels of total protein $(7.2 \mathrm{~g} / \mathrm{d} l)$, albumin $(3.4 \mathrm{~g} / \mathrm{m} l)$, globulin $(3.8 \mathrm{~g} / \mathrm{d} l)$, blood urea nitrogen $(16.6 \mathrm{mg} / \mathrm{d} l)$ and creatinine $(0.8 \mathrm{mg} / \mathrm{d} l)$. There were no abnormalities at the bladder by the rectal palpation and umbilical cord with the ultrasound scanner (HS-101V, Honda, Toyohashi, Japan). Animals were cared for according to the Guide for the Care and Use of Laboratory Animals of the Joint Factory of the Veterinary Medicine, Kagoshima University.

CT imaging of the intra-abdomen was performed under deep sedation with $2 \%$ xylazine (xylazine $2 \%$, Fujita, Tokyo, Japan) injection. Image acquisition was obtained using a multi-slice helical CT scanner (Aquilion, Toshiba, Otawara, Japan). The gantry aperture in CT was $90 \mathrm{~cm}$. CT imaging was acquired at $2 \mathrm{~mm}$ collimation, a gantry rotation speed of $0.5 \mathrm{sec}, 120 \mathrm{kV}$ and $500 \mathrm{mAs} .100 \mathrm{ml}$ of iopamidol (oypalomin, Konica Minolta, Tokyo, Japan), with 370 mg/

*Correspondence to: Otomaru, K., Joint Faculty of Veterinary Medicine, Kagoshima University, 1-21-24 Korimoto, Kagoshima 890-0065, Japan. e-mail: otomaru@vet.kagoshima-u.ac.jp

(C)2015 The Japanese Society of Veterinary Science

This is an open-access article distributed under the terms of the Creative Commons Attribution Non-Commercial No Derivatives (by-nc-nd) License $<$ http://creativecommons.org/licenses/by-nc-nd/3.0/>. $\mathrm{m} l$ of iodine content, was infused into the urinary bladder using urethral catheter for the cystography. Pre-contrast CT images showed that round mass size was $22.9 \times 21.9 \mathrm{~cm}$, Hounsfield units of the cyst was 29.5 (five regions of interest above average), and the cyst was not attaching to the umbilicus (Fig. 1a and 1b). Hounsfield units of outer lobe of the right liver, renal cortex and the urinary bladder were 50.0, 35.0 and 10.0, respectively. Post-contrast CT images showed that the cyst was not attaching to the urinary bladder (Fig. 2a and $2 b$ ). Extirpative surgery was performed under general anesthesia with isoflurane (ISOFLU, DS Pharma Animal Health, Osaka, Japan). Through a posterior ventral midline incision, the cyst was removed (Fig. 3a). The size of cyst was almost the same, which was diagnosed by CT (Fig. 3b). The cyst was located at the edge of urachus without attaching to the urinary bladder and umbilicus. Escherichia coli was detected from the opalescent fluid inside the cyst using microbiological examination. Intravenous injection of ampicillin $2.5 \mathrm{~g}$ and cefazolin $2 \mathrm{~g}$ was conducted twice a day for 10 consecutive days following the surgery. The skin sutures were removed 10 days after the surgery, and then, the heifer returned to her home pen. During the ten-month follow-up, the heifer was doing well and did not show any clinical diseases.

Greene et al. [4] demonstrated that urachal remnants were classified into 4 types based on the morphological characteristics (Fig. 4). In the case of this heifer, it was confirmed that the cyst was not attaching to the urinary bladder or umbilicus using CT imaging and inspection during the surgery. Therefore, the case was diagnosed as urachal anomaly type 4 . Previous studies reported that brain cysts and pulmonary cysts in calves were diagnosed by CT $[2,9]$. In this study, the intra-abdominal cyst in heifer was diagnosed using the CT scanner with large gantry size and high radiation dose. Therefore, we could easily treat the cyst surgically. CT scans enabled measuring the diameter of the cyst in large production animal before the surgery for progress of medical science. The scans are simple and valuable non-invasive technique for diagnosis of intra-abdominal diseases in cattle. 


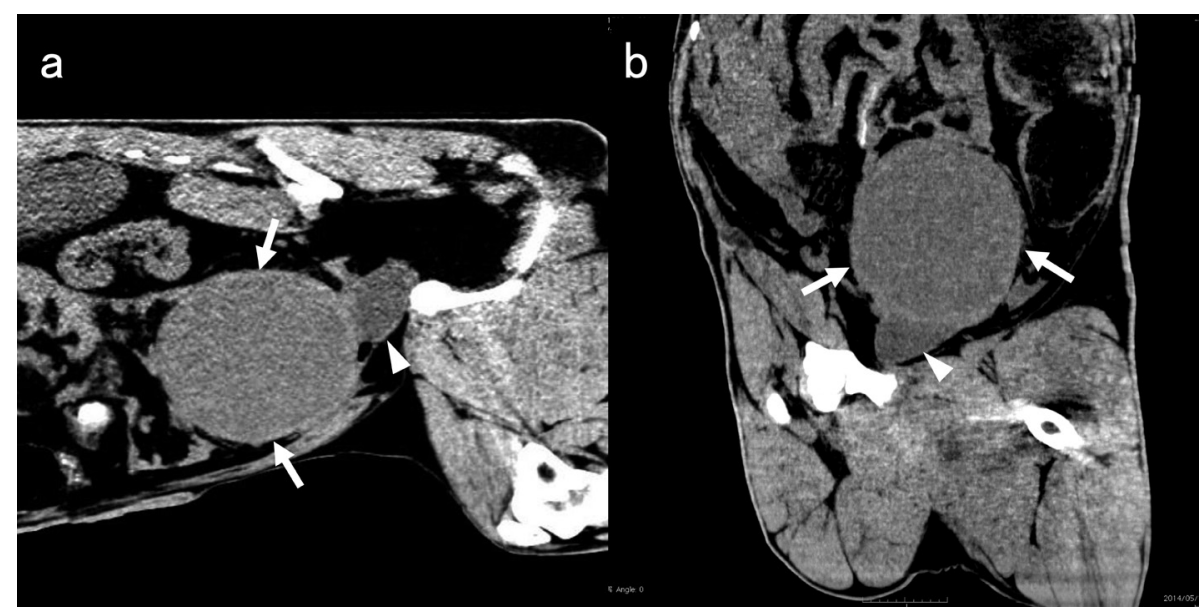

Fig. 1. Sagittal (a) and dorsal-plane (b) multiplanar recontruction CT images without contrast in heifer with abdominal cyst. Arrows show the presence of intra-abdominal cyst. The CT values in the lesion were 28-31 H.U. Arrowheads show the presence of urinary bladder.

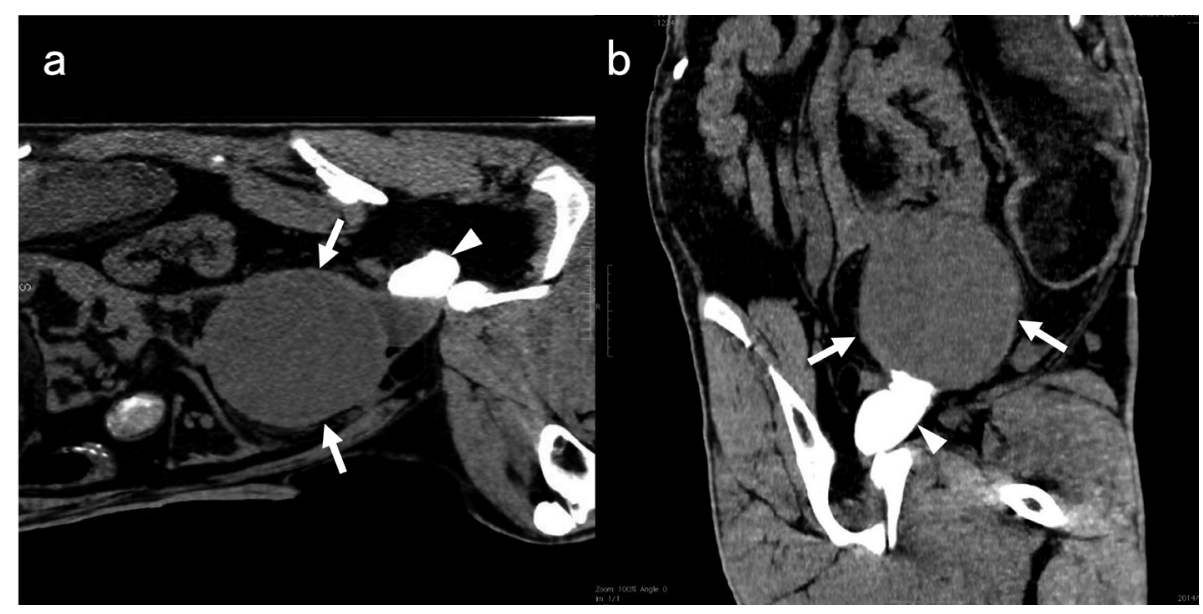

Fig. 2. Sagittal (a) and dorsal-plane (b) multiplanar recontruction CT images with post-contrast in heifer with abdominal cyst. Contrast medium was infused into the urinary bladder for the cystography. Arrows show the presence of intra-abdominal cyst. Arrowheads show the presence of urinary bladder.
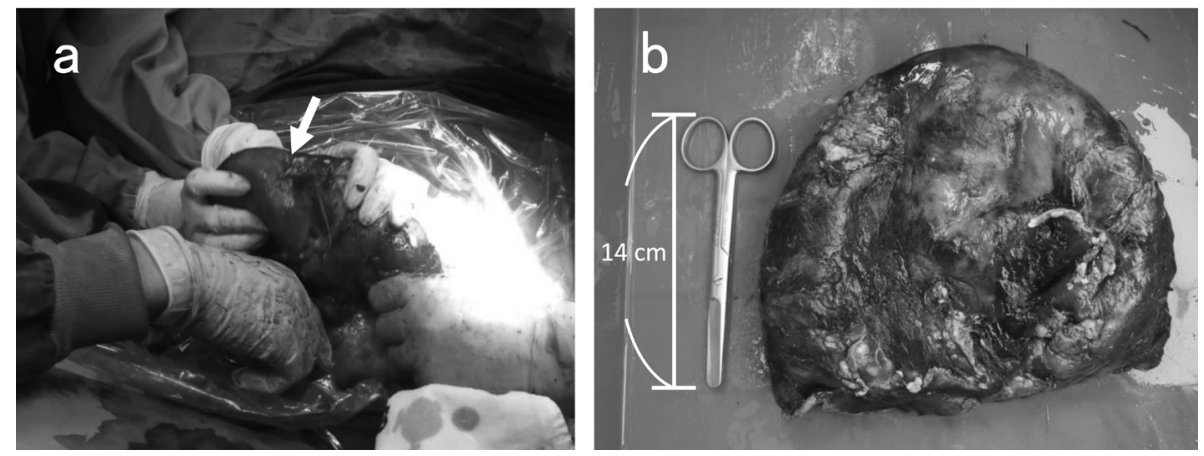

Fig. 3. Peroperative (a) and extraction of the abdominal cyst (b) photography. Arrow shows the presence of abdominal cyst. 
Type 1

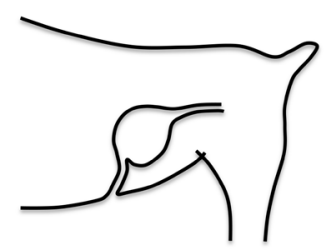

Type 3

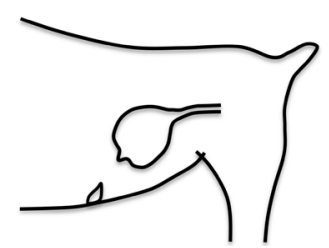

Type 2

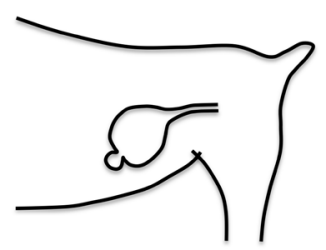

Type 4

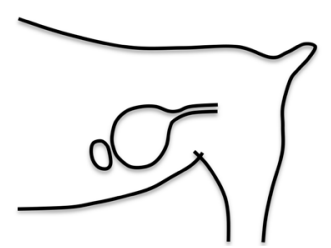

Fig. 4. Four types of urachal anomalies. Type 1; the urachus communicates with the bladder and umbilicus, Type 2; the urachus fails to close completely at the bladder, Type 3; A urachal sinus is formed at the umbilicus, Type 4; A totally blind urachal cyst. These figures were taken from the report by Greene et al. [4].

ACKNOWLEDGMENT. The authors are grateful to DVM Shinichi Jomori of Nansatsu Agricultural Mutual Aid Associations in Kagoshima prefecture, Japan, for providing the heifer for this study.

\section{REFERENCES}

1. de Battisti, A., Harran, N., Chanoit, G. and Warren-Smith, C. 2013. Use of negative contrast computed tomography for diagnosis of a colonic duplication in a dog. J. Small Anim. Pract. 54: 547-550. [Medline]

2. El-Khodery, S., Yamada, K., Aoki, D., Kamio, K., Kishimoto,
M., Shimizu, J., Kobayashi, Y., Ishii, M., Inokuma, H., Yamauchi, S. and Matsui, T. 2008. Brain abscess in a Japanese black calf: utility of computed tomography (CT). J. Vet. Med. Sci. 70: 727-730. [Medline] [CrossRef]

3. Engelmann, N., Ondreka, N., Michalik, J. and Neiger, R. 2014. Intra-abdominal Mycobacterium tuberculosis infection in a dog. J. Vet. Intern. Med. 28: 934-938. [Medline] [CrossRef]

4. Greene, R. W. and Scott, R. C. 1975. Lower urinary tract disease. pp. 1541-1577. In: Textbook of Veterinary Internal Medicine, 2nd ed. (Ettinger, S. J. ed.), WB Saunders, Philadelphia.

5. Hoey, S., Drees, R. and Hetzel, S. 2013. Evaluation of the gastrointestinal tract in dogs using computed tomography. Vet. Radiol. Ultrasound 54: 25-30. [Medline] [CrossRef]

6. Inaba, M., Katho, H., Koiwa, M., Sakai, T., Higasa, Y., Yamagishi, N. and Wada, Y. 2014. The calf: medicine from the birth to first childbirth. The Society of Farm Animal in Infectious Diseases, Tokyo (in Japanese).

7. Israel, R. S., McDaniel, P. A., Primack, S. L., Salmon, C. J., Fountain, R. L. and Koslin, D. B. 1996. Diagnosis of diaphragmatic trauma with helical CT in a swine model. AJR Am. J. Roentgenol. 167: 637-641. [Medline] [CrossRef]

8. Köhler, C., Jopp, I., Bosch, B., Pfeifer, S., Alef, M., Oechtering, G. and Kiefer, I. 2012. Liver abscess in a dog. A case report. Tierarztl. Prax. Ausg. K Kleintiere. Heimtiere 40: 211-218. [Medline]

9. Lee, K. J., Kishimoto, M., Shimizu, J., Kobayashi, Y., Matsumoto, K., Sasaki, N., Ishii, M., Inokuma, H., Iwasaki, T., Miyake, Y. and Yamada, K. 2011. Use of contrast-enhanced CT in the diagnosis of abscesses in cattle. J. Vet. Med. Sci. 73: 113-115. [Medline] [CrossRef]

10. Nogradi, N., Magdesian, K. G., Whitcomb, M. B., Church, M. and Spriet, M. 2013. Imaging diagnosis-aortic aneurysm and ureteral obstruction secondary to umbilical artery abscessation in a 5-week-old foal. Vet. Radiol. Ultrasound 54: 384-389. [Medline] [CrossRef]

11. Schwarz, T and Saunders, J. 2011. Veterinary Computed Tomography, Wiley-Blackwell, Oxford. 